\title{
EL CRECIMIENTO URBANO DE TANDIL: ¿MODELO TERRITORIAL DE LA CIUDAD DIFUSA?
}

TANDIL URBAN GROWTH: ¿TERRITORIAL MODEL OF THE DIFFUSE CITY?

\author{
MsC Guillermina Fernández \\ Profesora Adjunta. Facultad de Ciencias Humanas. UNCPBA. Tandil. Argentina
}

MsC Aldo G. Ramos

Ayudante de docencia. Facultad de Ciencias Humanas. UNCPBA. Tandil. Argentina

\section{Resumen}

Tandil, es una ciudad intermedia de la Provincia de Buenos Aires que ha crecido de forma continua y heterogénea. Este crecimiento de los últimos 50 años refleja la expansión sobre distintas áreas. En las últimas dos décadas se observa un mayor crecimiento sobre los faldeos serranos de forma dispersa o en fajas. Estos elementos permiten considerar la presencia de un modelo Urban Sprawl, de ciudad difusa o dispersa. Patrones territoriales, de conectividad, densidad o concentración pueden indicar, a priori, un tipo de crecimiento que consume mucho espacio. Es el producto de un uso espontáneo del territorio a partir de una fuerte especulación inmobiliaria. Pero también es el resultado de una planificación que permite la diferenciación espacial entre el Norte y el Sur de la ciudad.

Palabras claves: Crecimiento urbano, modelos de expansión, ciudad difusa, urbanización, urban sprawl.

\begin{abstract}
.
Tandil is a medium sized city in the province of Buenos Aires has grown continuously and heterogeneous. This growth in the last 50 years reflects the expansion of different areas. In the last two decades there has been a greater growth on mountain slopes or in scattered strips.. These elements allow us to consider the presence of a model Urban Sprawl, diffuse or dispersed city. Territorial patterns, connectivity, density or concentration may indicate, a priori, a type of growth that consumes a lot of space. It is the product of a spontaneous use of territory from strong speculation. But it is also the result of a plan that allows spatial differentiation between the North and South of the city.
\end{abstract}

Key words. Urban growth, expansion models, diffuse, urbanization, urban sprawl.

\section{Introducción:}

La ciudad de Tandil ha crecido paulatinamente, sin embargo dicho crecimiento espacial presenta variaciones en relación a las áreas de expansión o la continuidad o discontinuidad de la mancha urbana, las áreas sobre las que avanzó y la velocidad de crecimiento.

En tal sentido este trabajo pretende analizar un parte del proceso de expansión que refleja como ha sido ese crecimiento de la ciudad de Tandil y su manifestación en relación a un modelo de ciudad dispersa o conurbación difusa.

Para ello se elaboraron 5 mapas temáticos que plantean la secuencia de expansión urbana de la ciudad entre 1970 y el 2010, a partir de imágenes satelitales y fotos aéreas.

\section{Marco conceptual de referencia.}

El crecimiento urbano es polifacético y complejo y requiere del análisis de dimensiones diferentes. Incluye el crecimiento demográfico, económico, y físico de la ciudad. Por tal razón en este trabajo sólo se hace referencia a una dimensión del mismo, al aumento de la superficie urbanizada como respuesta a la demanda de suelo urbano para la localización de viviendas y actividades relacionadas.

Publicado en formato digital: MsC Guillermina Fernández y MsC Aldo G. Ramos. EL CRECIMIENTO URBANO DE TANDIL: ¿MODELO TERRITORIAL DE LA CIUDAD DIFUSA? Revista Geográfica Digital. IGUNNE. Facultad de Humanidades. UNNE. Año 10. No 20. Julio - Diciembre 2013. ISSN 1668-5180 Resistencia, Chaco.

En: http://hum.unne.edu.ar/revistas/geoweb/default.htm 
En relación a esto, la urbanización y los procesos asociados también requieren ser definidos. En tal sentido se puede definir a la urbanización como la cualidad de lo urbano. Y esto puede referir tanto al crecimiento como a la dotación de elemento funcionales en una ciudad (dotación de servicios e infraestructura, por ejemplo). Entonces la existencia de un crecimiento físico de la ciudad puede no significar un verdadero proceso de urbanización, al carecer de otros elementos que le otorgan la complejidad.

Ahora bien, en su forma más clásica la ciudad queda definida por su diferenciaron de las áreas rurales. Se presentan como un conjunto compacto de edificaciones, cuyos escasos intersticios estaban destinados al desplazamiento y al mercado inicialmente. El extensión del uso del automóvil, a mediados del siglo XX indujo la localización de actividades urbanas hacia la periferia, facilitando la aparición de una urbanización dispersa, cuya distancia al centro se amplía considerablemente con la construcción de redes de autopistas en torno a las grandes aglomeraciones, cinturones y radiales, que han extendido a territorios cada vez más amplios, el proceso de difusión urbana. Si bien este comportamiento es típico de áreas metropolitanas existen patrones de crecimiento que pueden observarse en ciudad de rango menor.

Por esto y dentro del contexto de las investigaciones en morfología urbana se observan planteamientos en torno a la dicotomía entre la ciudad compacta versus la ciudad dispersa, catalogando a esta última como la ciudad "fragmentada", "difusa", "confusa", "dual", etc. Este concepto ha sido analizado bajo la denominación de "urban sprawl". Reconociendo a este concepto como un desarrollo urbano disperso, separado de la periferia de las ciudades, sin coordinación y sin considerar los efectos sociales y ambientales que produce.

Para reconocer diferentes tipos de expansión discontinua, se puede analizar en términos de densidades de habitantes y de configuración espacial del asentamiento.

- El desarrollo continuo en baja densidad, es el de mayor consumo de territorio en los márgenes de áreas metropolitanas, transformándolo en suelo urbano. Este tipo de expansión se basa en la extensión sectorizada de las redes de infraestructura urbana como ser agua, electricidad, vialidad, etc. (Urbanismo de redes).

- El desarrollo en faja se da en la línea de los grandes corredores de transporte que salen de las zonas centrales de la ciudad. Las zonas adyacentes al corredor se desarrollan con usos urbanos, y las zonas alejadas al mismo mantienen su carácter rural. Con el tiempo esta tierra rural se convertirá en urbana, en la medida que surjan corredores transversales de transporte.

- El desarrollo discontinuo o en "salto de rana", son urbanizaciones discontinuas de los márgenes de áreas metropolitanas o de conurbaciones en faja. Este tipo de desarrollo es el que requiere de mayor inversión en servicios urbanos para poder materializarse.

- El desarrollo disperso extraurbano se asocia al concepto de expansión en vivienda de terrenos abiertos, en entornos naturales (agrícolas, forestales, etc.), más allá de los suburbios de la ciudad. Este tipo de residencia ha aumentado fuertemente en las últimas décadas. Este patrón de asentamiento ha sido también denominado "desarrollo en baja densidad extendido" y difiere significativamente de los patrones urbanos, de suburbios o rurales.

Entre los distintos efectos de la urbanización difusa o sprawl podemos encontrar los siguientes elaborados por el Environmental Law Institute (1) que a través de su programa de uso sustentable del suelo estableció un decálogo de los errores de la dispersión urbana (Ten Things Wrong With Sprawl), los cuales son:

- Debilitamiento de los equipamientos y servicios públicos. Se inducen fallas en el mercado pues los residentes dispersos tienen acceso a equipamientos públicos, por los cuales no pagan impuestos, siendo los antiguos residentes de dichas áreas las que justifican la existencia de estos equipamientos.

- Disminución del mantenimiento efectivo de las infraestructuras existentes. Los nuevos desarrollos urbanos dispersos demandan nuevas infraestructuras, las que deben ser financiadas en desmedro de los recursos disponibles para la mantención de la infraestructura previamente existente.

- Incremento de los costos sociales de transporte. Los costos aumentan significativamente, por las modificaciones necesarias para aumentar las capacidades de infraestructuras existentes, es decir, la construcción de infraestructuras paralelas. Estas modificaciones son permanentes en estructuras urbanas dispersas y son costeadas por cada residente a un alto valor.

Publicado en formato digital: MsC Guillermina Fernández y MsC Aldo G. Ramos. EL CRECIMIENTO URBANO DE TANDIL: ¿MODELO TERRITORIAL DE LA CIUDAD DIFUSA? Revista Geográfica Digital. IGUNNE. Facultad de Humanidades. UNNE. Año 10. NN 20. Julio - Diciembre 2013. ISSN 1668-5180 Resistencia, Chaco.

En: http://hum.unne.edu.ar/revistas/geoweb/default.htm 
Revista Geográfica Digital. IGUNNE. Facultad de Humanidades. UNNE. Año 10. № 20.

Julio - Diciembre 2013. ISSN 1668-5180 Resistencia, Chaco

- Consumo de mayor cantidad de recursos que otros patrones de desarrollo urbano. Porque los usos están más separados, es decir, se requiere más insumos para su conexión (concreto, asfalto, cables, energía, etc.).

- Incremento de los gastos en el tiempo. Dado el mayor gasto en tiempo de transporte, la separación y especialización de los usos tiene efectos adversos en el barrio, al aumentar los viajes en automóvil.

- Degradación de la calidad del aire y del agua. Al utilizar el recurso agua, primero disminuye la disponibilidad para las actividades del entorno (altamente dependientes del recurso), además de inyectar agua utilizada a las napas, con el riesgo que eso trae. La atmósfera se ve afectada por los altos flujos de transporte, que como fuentes móviles dispersan en el territorio sus distintos tipos de emisión.

- Alteración o destrucción permanente de los hábitats naturales. Se cubren grandes áreas con asfaltos, concretos y estructuras que alteran la red hidrológica, y reducen la productividad biológica del territorio.

También es necesario considerar que las áreas de expansión avanzan sobre zonas del emplazamiento de una ciudad que ofrecen limitaciones constructivas o situación de vulnerabilidad geológica, hidrológica, que generan luego problemáticas para la dotación de servicios, para el saneamiento, para la organización de la trama, e incluso perdida de calidad. A esto se suma que en ocasiones la supervivencia de usos del suelo, sean estos residuales o activos, producto de la configuración urbana anterior, básicamente rural (agrícola, ganadera, minero extractiva, etc.) genera incompatibilidad de usos del suelo, lo que determina un aumento en la vulnerabilidad y en ocasiones nuevas amenazas que convierten a estos espacios en áreas de riesgo. Cerda Troncoso (2) señala que los aspectos que hacen al desarrollo de un proceso de crecimiento disperso o sprawl son:

- Desarrollos en franjas o en saltos de rana

- Hábitats y patrones de localización de usos fragmentados

- Mala accesibilidad entre usos de suelo adyacentes y segregados

- Grandes espacios sin funcionalidad

- Dependencia del automóvil y baja participación del transporte público

- Conversión rural-urbana a mayor tasa que el crecimiento poblacional

- Mayores tasas de consumo de energía, que en formas compactas de desarrollo

- Aumento de tiempo, impuestos y costos en la entrega de servicios públicos

Teniendo en cuenta los mecanismos para evaluar los fenómenos de dispersión se consideran los siguientes atributos claves a ser considerados.

Para Galster (3), las dimensiones que caracterizan el fenómeno sprawl son densidad, continuidad, concentración, compactación, centralidad, nuclearidad, diversidad y proximidad. Como la dispersión es un patrón de expansión urbana, presenta bajos niveles en algunas o en todas, de las ocho dimensiones definidas. Esta definición da la posibilidad de que puedan existir distintos tipos de sprawl, dependientes de las diferentes combinaciones de las dimensiones.

- Densidad: corresponde al número promedio de unidades residenciales por unidad de superficie cuadrada de suelo desarrollable.

- Continuidad: es el grado en el que un tipo de uso de suelo se desarrolla con densidad continua (sin quiebres o saltos de rana).

- Concentración: es el grado en que el desarrollo se ha localizado en relativamente pocos $\mathrm{Km}^{2}$, del total de $\mathrm{Km}^{2}$ del área urbana.

- Compactación: es el grado en que el desarrollo se ha "clusterizado" (aglomerado), para minimizar la cantidad de suelo en cada $\mathrm{km}^{2}$ de suelo desarrollable ocupado por uso residencial y no residencial.

- Centralidad: es el grado en que el desarrollo residencial y no residencial se ha localizado cerca del CBD (Central Business District) del área urbana

- Nuclearidad: es la extensión espacial en la que el área urbanizada se caracteriza por tener un solo núcleo funcional (en contraste con un patrón polinucleado).

Publicado en formato digital: MsC Guillermina Fernández y MsC Aldo G. Ramos. EL CRECIMIENTO URBANO DE TANDIL: ¿MODELO TERRITORIAL DE LA CIUDAD DIFUSA? Revista Geográfica Digital. IGUNNE. Facultad de Humanidades. UNNE. Año 10. NN 20. Julio - Diciembre 2013. ISSN 1668-5180 Resistencia, Chaco.

En: http://hum.unne.edu.ar/revistas/geoweb/default.htm 
- Diversidad: es el grado en que dos usos distintos (residencial y no residencial) existen en una misma zona y la extensión del área urbanizada que cumple con esta característica de diversidad.

- Proximidad: es el grado en que distintos usos de suelo están cercanos entre si, en el área urbanizada. La proximidad es máxima cuando todas las zonas con altas densidades de un uso están cercanas, unas de otras. Bajos niveles de proximidad de dos usos se asocia a sprawl.

\section{Caracterización del área de estudio.}

Tandil se localiza en el sureste de la Provincia de Buenos Aires (República Argentina). Se encuentra a $350 \mathrm{Km}$. de la ciudad de Buenos Aires y la población actual supera los 120.000 habitantes (Censo 2010). El Partido de Tandil está emplazado en la Pampa Húmeda y más precisamente, en el sistema serrano de Tandilia, que lo atraviesa en sentido NO-SE.

Este sistema orográfico se halla caracterizado por un conjunto de serranías bajas y de formas redondeadas en el Centro y Norte del partido, mientras que cambian a formas de mesas o tabulares hacia el Oeste y Sur.

Con respecto al emplazamiento, la ciudad se extiende de forma irregular, en una superficie aproximada de $50 \mathrm{~km}^{2}$, y cuyo soporte se caracteriza por ser una encrucijada de valles que descienden desde las Sierras de Tandil hacia la llanura Norte, continuándose hasta la depresión del Río Salado.

Figura 1: Localización de la ciudad de Tandil en la Provincia de Buenos Aires y Argentina.

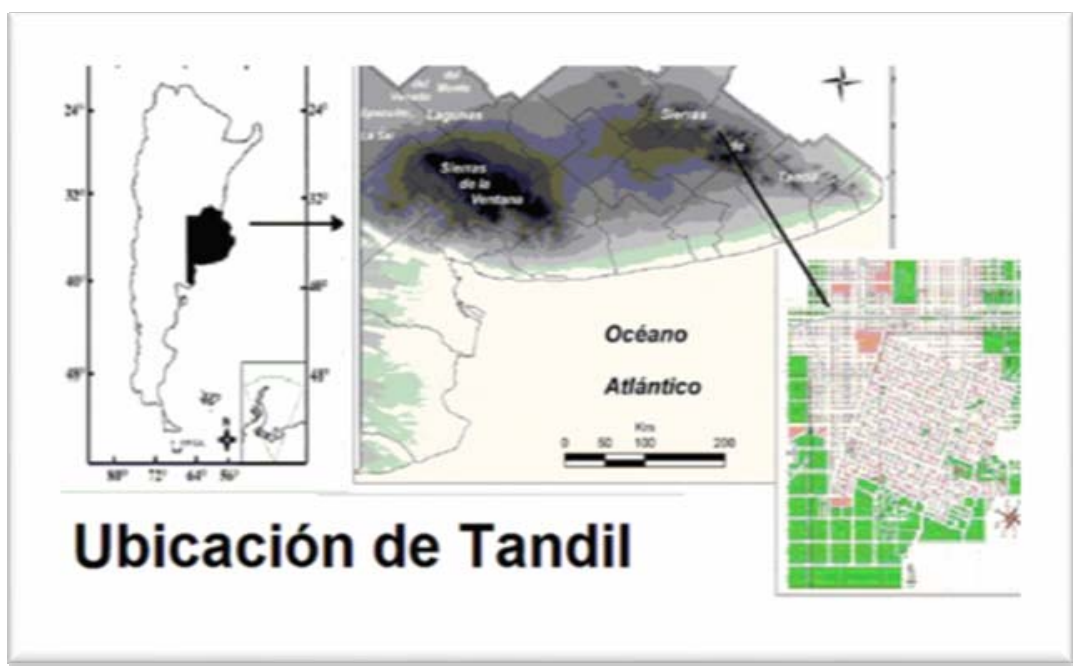

Fuente: elaboración personal en base a imágenes de la WEB

Secuencia de mapas temáticos. Análisis de la evolución de la planta urbana de la ciudad de Tandil (1970-2010) y su relación con las áreas mineras cercanas.

La planta urbana consolidada con mayor densidad edilicia para 1970 se encontraba ubicada en el piedemonte proximal del conjunto serrano recostado en los faldeos del $\mathrm{O}$ y en segundo término del SO y $\mathrm{S}$, tal como se puede apreciar en el mapa $\mathrm{N}^{\circ} 1$.

Publicado en formato digital: MsC Guillermina Fernández y MsC Aldo G. Ramos. EL CRECIMIENTO URBANO DE TANDIL: ¿MODELO TERRITORIAL DE LA CIUDAD DIFUSA? Revista Geográfica Digital. IGUNNE. Facultad de Humanidades. UNNE. Año 10. No 20. Julio - Diciembre 2013. ISSN 1668-5180 Resistencia, Chaco.

En: http://hum.unne.edu.ar/revistas/geoweb/default.htm 


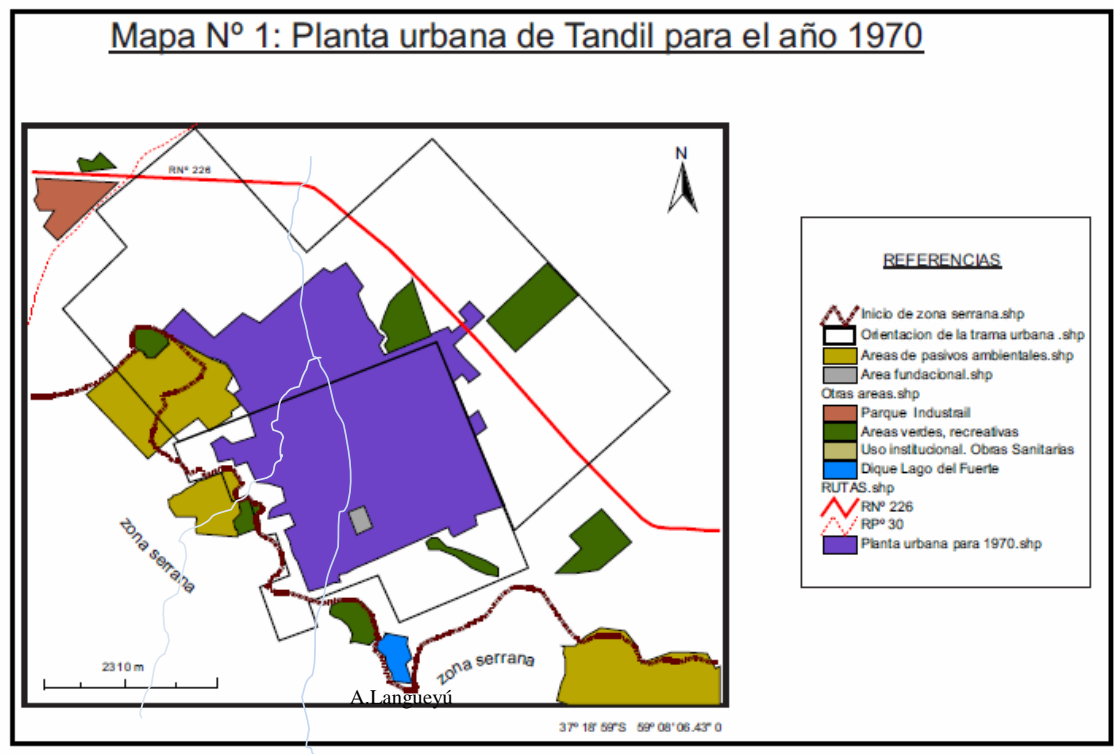

Fuente: Elaboración personal en base a fotografías aéreas y planos del Plan de Ordenamiento territorial del Tandil 2005.

El área fundacional asociada a la Plaza Central se ubicaba en la zona SO dentro de la mancha urbana que se distribuía casi totalmente al sur de la RN 226. En relación a las áreas mineras que aún estaban en explotación puede observarse la proximidad del ejido urbano sobre todo a los emprendimientos ubicados en torno al cerro de La Movediza y la Cantera Los Nogales, según datos de catastro complementarios. En relación al Arroyo Langueyú puede observarse como la ciudad se emplaza en el valle de dicho curso de agua, en ambas márgenes.

Para 1980, según el mapa $\mathrm{N}^{\circ} 2$, se puede observar el crecimiento principalmente hacia el sector $\mathrm{N}$ $\mathrm{NO}$ y NE, incorporando a la RN 226, y la acentuación de un modelo de dirección de las calles diferente al cuadrante central. Aunque con una superficie menor se denota una expansión sobre los faldeos serranos del S y SO del "borde serrano".

En esta etapa se consolida una expansión urbana en mancha con velocidades de crecimiento diferentes y una tendencia a la consolidación del tejido urbano sobre el sector cercano a la RN 226. Esto se asocia a la disponibilidad de suelo llano para la expansión de la ciudad.

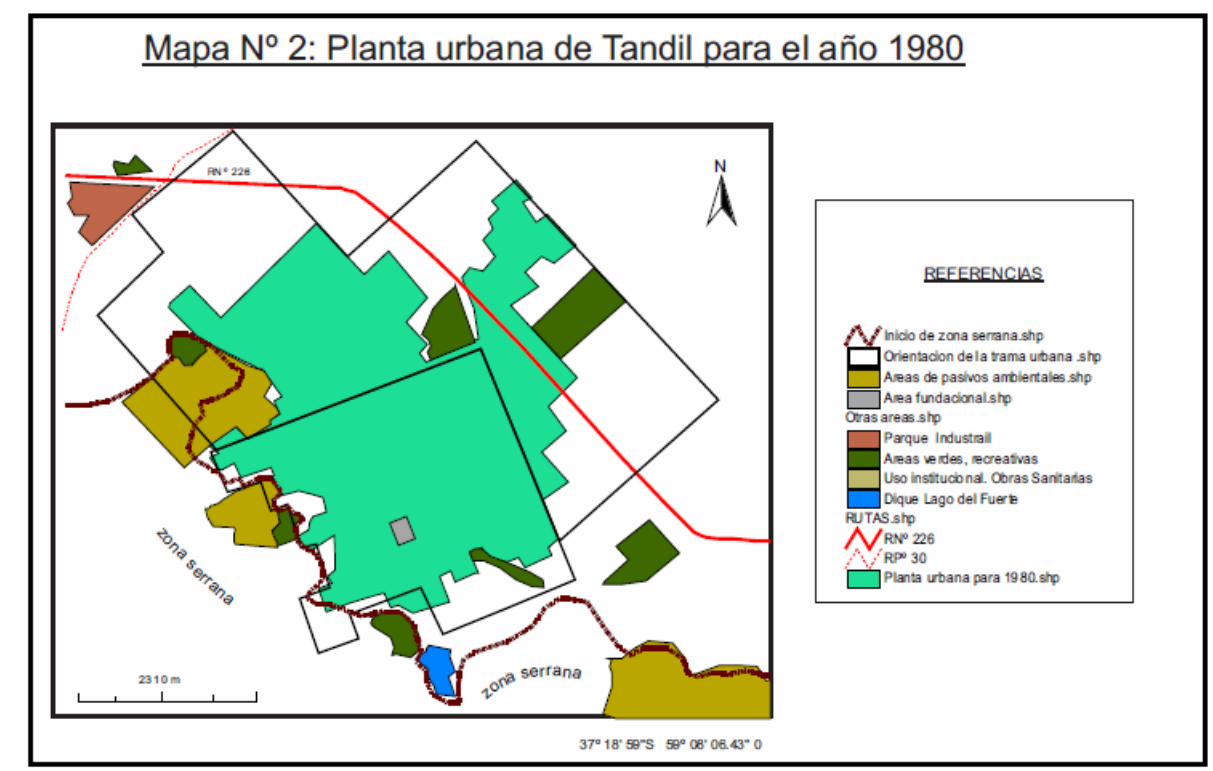

Fuente: Elaboración personal en base a fotografías aéreas y planos del Plan de Ordenamiento territorial del Tandil 2005.

Publicado en formato digital: MsC Guillermina Fernández y MsC Aldo G. Ramos. EL CRECIMIENTO URBANO DE TANDIL: ¿MODELO TERRITORIAL DE LA CIUDAD DIFUSA? Revista Geográfica Digital. IGUNNE. Facultad de Humanidades. UNNE. Año 10. No 20. Julio - Diciembre 2013. ISSN 1668-5180 Resistencia, Chaco.

En: http://hum.unne.edu.ar/revistas/geoweb/default.htm 
Patrones territoriales

\begin{tabular}{ll} 
Densidad & Según las imágenes existe mayor densidad sobre la zona N-NO \\
\hline continuidad & $\begin{array}{l}\text { La zona NO presenta mayores rasgos producto de su relación con la zona } \\
\text { central de la ciudad }\end{array}$ \\
concentración & $\begin{array}{l}\text { Hay una tendencia en la zona NNO pero la superficie ocupada es baja en } \\
\text { relación a la superficie total de la ciudad, no tiende a la concentración. }\end{array}$ \\
$\begin{array}{ll}\text { compactación } & \text { No existe este proceso. } \\
\text { centralidad } & \text { Si bien los desarrollos urbanos no están alejados se ubican en su mayor parte } \\
\text { en la zona mas alejada del centro urbano. Esto es importante por la } \\
\text { conectividad del centro y la periferia. }\end{array}$ \\
$\begin{array}{ll}\text { nuclearidad, } \\
\text { La zona NNO esta vinculada a un segundo centro funcional de la ciudad que si } \\
\text { bien no aparece en el mapa posee servicios descentralizados y uso comercial } \\
\text { como factores de atractividad. Corresponde a la zona del Barrio de Villa Italia. }\end{array}$ \\
$\begin{array}{ll}\text { proximidad } & \text { Solo se panaliza. } \\
& \text { a áreas mineras abandonadas o inactivas. }\end{array}$ \\
\hline
\end{tabular}

Para 1990 (mapa $N^{\circ} 3$ ) la trama, en constante expansión, avanza principalmente sobre el área serrana del NO del ejido urbano. Según fuentes secundarias complementarias (cartas topográficas) coincidente con el área del Cerro de La Movediza y se aproxima a la zona minera por el sector oeste, siguiendo algunas arterias de comunicación. Se evidencia, un proceso incipiente de crecimiento sobre el área serrana del SO y un avance hacia los faldeos serranos del sur, que en proporción son las áreas con mayor crecimiento.

Coincide además con la mayor densidad, centralidad y continuidad espacial. Por el contrario en la zona NO persiste un uso rural y la proximidad entre usos del suelo urbano es menor.

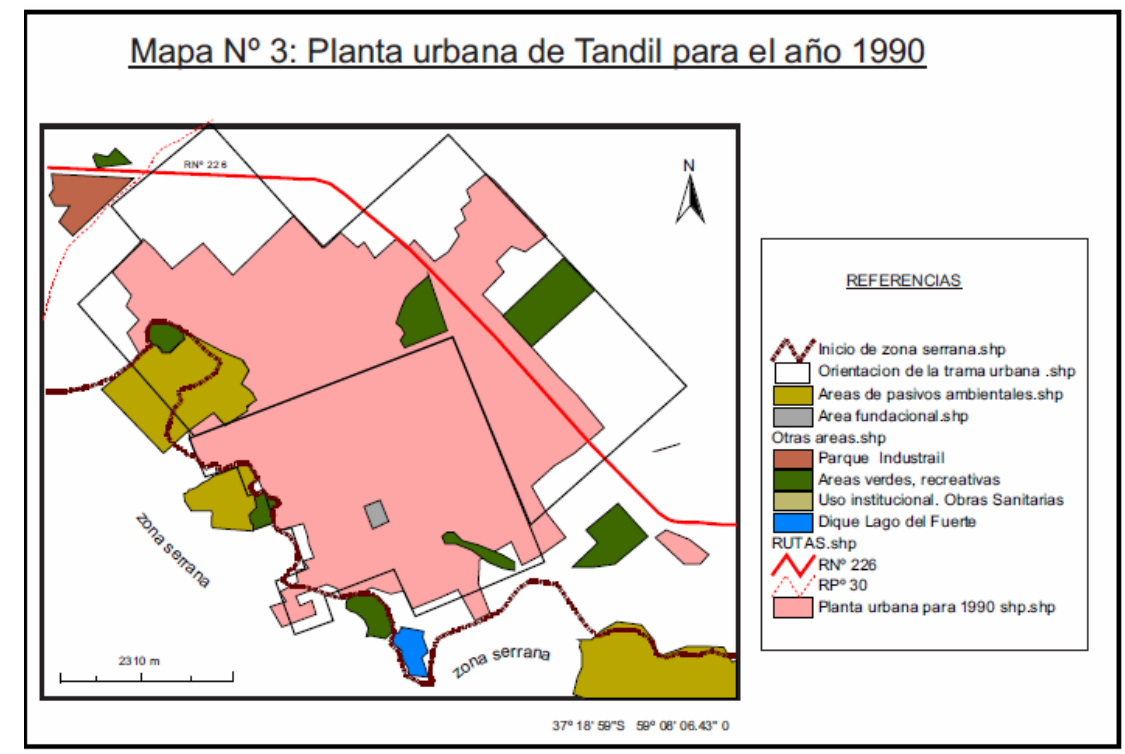

Fuente: Elaboración personal en base a fotografías aéreas y planos del Plan de Ordenamiento territorial del Tandil 2005.

Se observa además que se densifica la zona en torno a la ruta N 226 en ambos lados, con uso residencial pero fundamentalmente comercial, vinculado al sector rural, construcciones, transporte etc. Hacia el año 2000 como se observa en el mapa $N^{\circ} 4$, la mancha urbana crecía y claramente consolidaba los espacios anteriores y avanzaba hacia los faldeos serranos que hasta ese momento se comportaban como líneas de fijación. La mayor evidencia de esto se encuentra en las áreas al S. $\mathrm{SO}$ y $\mathrm{O}$. Sin embargo puede verse que el sector $\mathrm{N}$ y NE también presenta crecimiento. Son dos modelos diferentes, uno hacia el llano y el otro sobre el piedemonte serrano. Se evidencia un claro

Publicado en formato digital: MsC Guillermina Fernández y MsC Aldo G. Ramos. EL CRECIMIENTO URBANO DE TANDIL: ¿MODELO TERRITORIAL DE LA CIUDAD DIFUSA? Revista Geográfica Digital. IGUNNE. Facultad de Humanidades. UNNE. Año 10. No 20. Julio - Diciembre 2013. ISSN 1668-5180 Resistencia, Chaco.

En: http://hum.unne.edu.ar/revistas/geoweb/default.htm 
cambio en el sentido del crecimiento urbano sobre el sector SE y S que se asocia con usos residenciales abiertos y emprendimientos más alejados del centro sin continuidad espacial. Modelo que se acentúa para el año 2010.

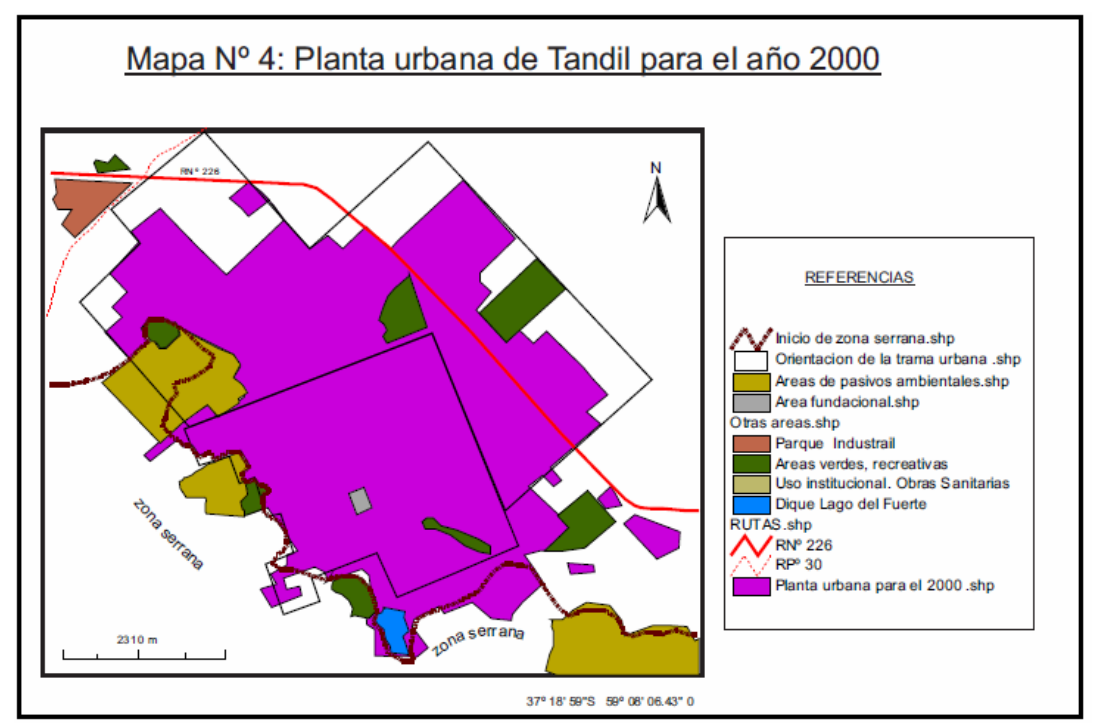

Fuente: Elaboración personal en base a fotografías aéreas y planos del Plan de Ordenamiento territorial del Tandil 2005.

Se evidencia el crecimiento hacia las áreas que contienen espacios mineros inactivos de diferente antigüedad, en un avance sobre las áreas serranas para uso residencial.

En el último mapa, correspondiente al 2010 es notorio el avance sobre el sector S y SE de la mancha urbana, la consolidación de espacios en relación a la ruta $N^{\circ} 226$ y la zona en torno al lago del Fuerte. $\mathrm{Sin}$ embargo se mantiene el crecimiento cercano al Parque industrial y la ruta $\mathrm{N}^{\circ} 226$. En espacios vacantes entre el ejido urbano principal y dicha arteria.

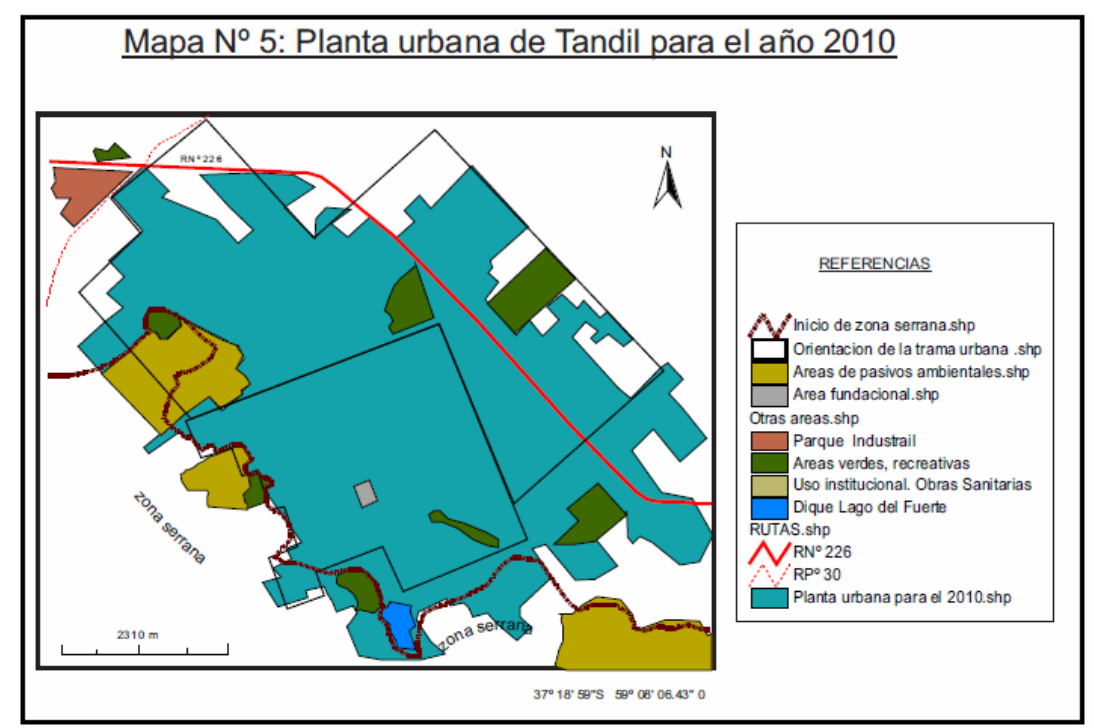

Fuente: Elaboración personal en base a fotografías aéreas y planos del Plan de Ordenamiento territorial del Tandil 2005.

A través de la cartografía temática complementaria, se puede observar que se acentúa un modelo de crecimiento por uso residencial de diferente tipología. Mientras en la zona Sur se evidencian barrios

Publicado en formato digital: MsC Guillermina Fernández y MsC Aldo G. Ramos. EL CRECIMIENTO URBANO DE TANDIL: ¿MODELO TERRITORIAL DE LA CIUDAD DIFUSA? Revista Geográfica Digital. IGUNNE. Facultad de Humanidades. UNNE. Año 10. NN 20. Julio - Diciembre 2013. ISSN 1668-5180 Resistencia, Chaco.

En: http://hum.unne.edu.ar/revistas/geoweb/default.htm 
planificados, en otros son usos de tipo más abierto, barrio-jardín e incluso barrios cerrados o semicerrados. En esta etapa desaparece la continuidad de la trama para dispersarse en manchas sobre diferentes áreas, la mayoría de ellas en torno a los faldeos serranos.

Por último se plantea el Mapa $N^{\circ} 6$ donde se integran los cinco cortes y se observa con más claridad la proyección del crecimiento.

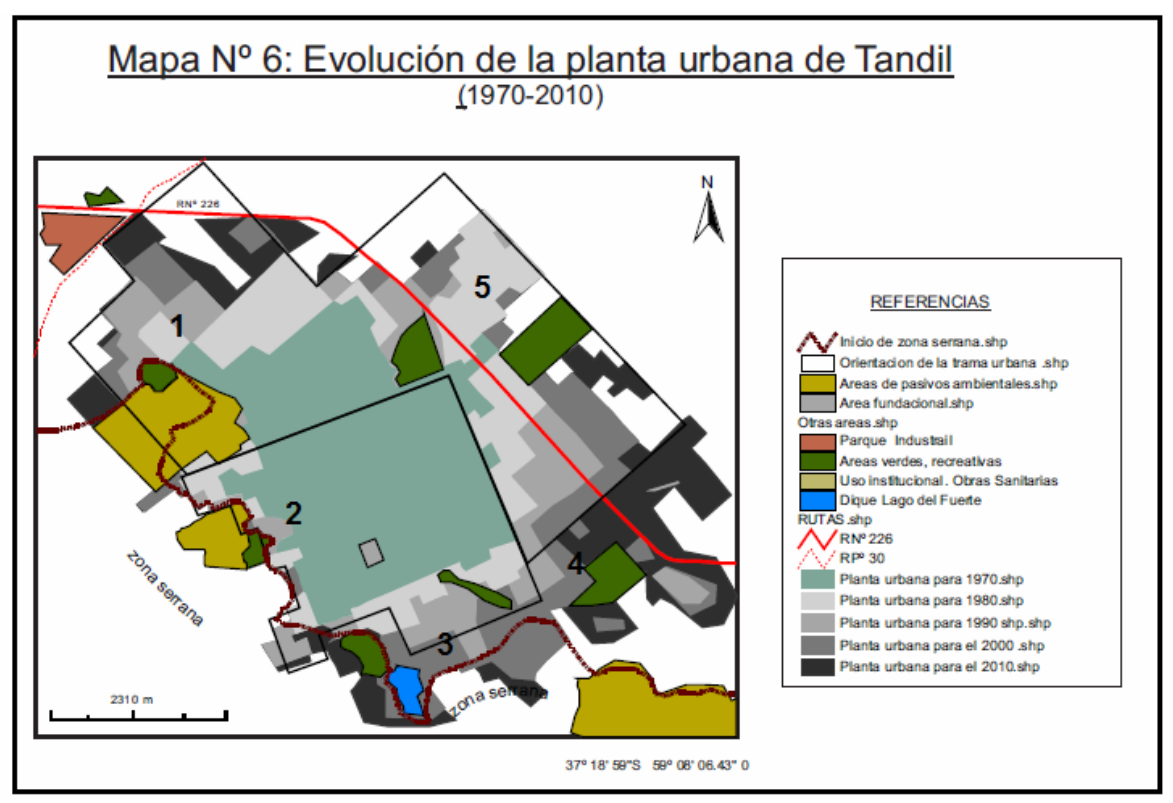

Fuente: Elaboración personal en base a fotografías aéreas y planos del Plan de Ordenamiento territorial del Tandil 2005

Es evidente que a lo largo del tiempo se producen dos procesos, en las décadas de 1970 y 1980 se consolida el crecimiento sobre el área norte, coincidente con espacios de piedemonte distal hacia la llanura, mientras que desde 1990 en adelante se evidencia un incremento notorio de la mancha urbana sobre las sierras. Esta dinámica es clave para comprender como este modelo de ciudad difusa se extiende sobre las sierras y sobre las zonas más llanas y esto supone requerimientos y procesos de planificación basados en diagnósticos diferenciales e impactos socioterritoriales y ambientales diferentes. La secuencia de imágenes permite observar la expansión en las diferentes etapas y su morfología actual.

Publicado en formato digital: MsC Guillermina Fernández y MsC Aldo G. Ramos. EL CRECIMIENTO URBANO DE TANDIL: ¿MODELO TERRITORIAL DE LA CIUDAD DIFUSA? Revista Geográfica Digital. IGUNNE. Facultad de Humanidades. UNNE. Año 10. NN 20. Julio - Diciembre 2013. ISSN 1668-5180 Resistencia, Chaco.

En: http://hum.unne.edu.ar/revistas/geoweb/default.htm 
Figura 2. Evolución de la planta urbana de Tandil a partir de imágenes satelitarias desde 1970 hasta 2010.

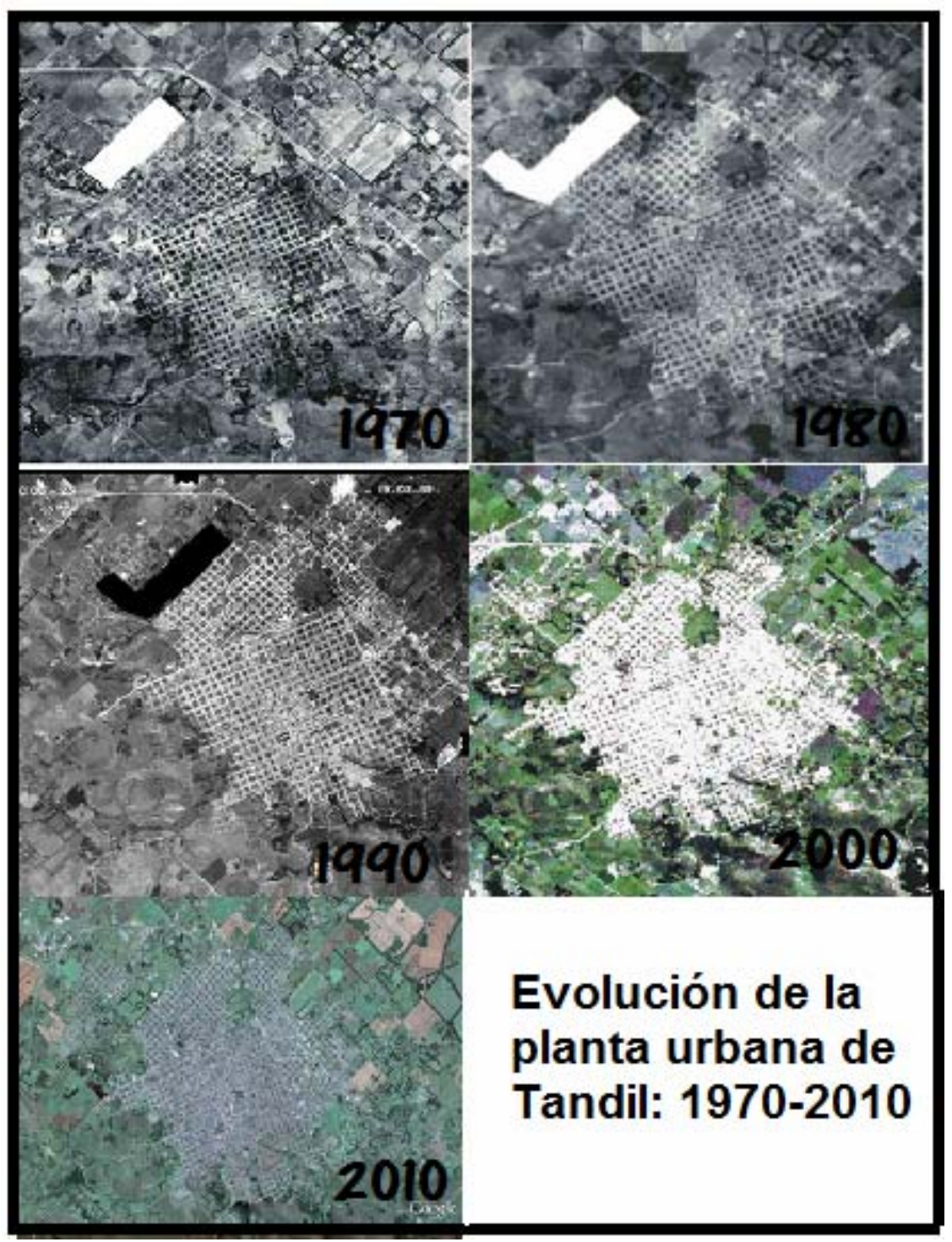

Fuente: Elaboración personal en base a imágenes satelitales Google Earth y fotografía aéreas

Esta expansión permite observar como la ciudad crece en forma de mancha de aceite extendiéndose sobre las áreas serranas y sobre los espacios residuales de la actividad minera canteril y áreas de uso recreativo en las sierras. Esto ha cambiado la línea de fijación que supera la cota de $200 \mathrm{msnm}$

\section{Caracterización actual de las áreas urbanizadas:}

\section{Área Noroeste:}

El crecimiento urbano operado en la última década, está fundamentalmente relacionado con la ocupación del área localizada entre el consolidado urbano y las RN 226, RP 30 y el Parque Industrial, entrando en contacto con el $\mathrm{B}^{\circ}$ Cerro Leones. En el sector se aprecian conjuntos habitacionales promovidos por el Estado y viviendas unifamiliares de baja calidad. La escasa dotación de ciertos equipamientos y servicios, la ausencia de espacios verdes, los problemas vinculados al medio físico y la lejanía del centro, configuran un sector complejo y problemático, originalmente vinculado a la actividad minera. A ello se le suman actividades propias de franjas periurbanas degradadas (ej.

Publicado en formato digital: MsC Guillermina Fernández y MsC Aldo G. Ramos. EL CRECIMIENTO URBANO DE TANDIL: ¿MODELO TERRITORIAL DE LA CIUDAD DIFUSA? Revista Geográfica Digital. IGUNNE. Facultad de Humanidades. UNNE. Año 10. NN 20. Julio - Diciembre 2013. ISSN 1668-5180 Resistencia, Chaco.

En: http://hum.unne.edu.ar/revistas/geoweb/default.htm 
desarmaderos de automóviles, circuito de motociclismo, fabricación de ladrillos, explotaciones mineras, criaderos de cerdos y la proximidad con el Parque Industrial y Cerro Leones).

Zona Cerro Movediza (zona 1 en mapa $\mathrm{N}^{\circ} 6$ ):

El área es eminentemente urbana, en proceso de expansión. Predomina el uso residencial de densidad media, y de baja densidad hacia el oeste, con barrios planificados (municipales y privados). También barrios consolidados vinculados a la fuerte presencia del ejército que tiene allí sus cuarteles y las residencias de los oficiales y suboficiales. Al uso residencial, se agrega el uso recreativo del cerro de La Movediza, paseo tradicional de Tandil, desde donde se puede tener una vista de la ciudad y su entorno. La dominancia visual que ejerce el cerro deja expuesto uno de los pasivos ambientales (Cantera El Trincante o Villa Mónica) que ponen en evidencia la relación con el resto de la ciudad, su cercanía, el vínculo con el ferrocarril y con las tecnologías de explotación (trituradoras, tolveras). Coexisten pasivos mineros, con áreas dentro de la cantera que mantienen una actividad industrial de trituración de piedra que es traída de otros yacimientos.

El Plan de Ordenamiento identifica el área como periurbana en proceso de consolidación, con un avance del uso residencial de media a alta densidad, manteniendo el uso recreativo. Esta área se encuentra muy cercana al ejido urbano consolidado y a una de las vías de acceso a la ciudad (RP 30).

\section{$\underline{\text { Área Oeste- Suroeste }}$}

Zona Calvario (zona 2 en mapa $N^{\circ} 6$ ).

Presenta dos áreas definidas de uso urbano y periurbano. Predomina el uso residencial con un importante avance de la construcción sobre el sector serrano. Dicho uso de alta y media densidad, esta conformado por barrios parquizados (abiertos) y conjuntos habitacionales planificados (Iniciativas de desarrollos públicos y privados). Hay además un uso recreativo fuertemente vinculado a la trama urbana, el cerro Monte Calvario, paseo religioso tradicional, hito de Tandil. Sin embargo, la urbanización va avanzando hacia la zona donde se encuentran los pasivos ambientales. Hacia el oeste, sur-oeste (limitando con el área 6) predominan parcelamientos de mayor tamaño con la presencia de complejos de cabañas y casas-quinta que conviven con algunos usos agrícolas intensivos propios del área periurbana.

En toda el área pueden observarse pasivos ambientales asociados a destapes y frentes de cantera abandonados. Entre ellos se destacan los tres frentes de cantera ubicados en cercanías del área recreativa y que incluyen a su vez maquinaria y restos de vías férreas pertenecientes a la cantera Los Nogales. El sector ubicado más al sur es un área de tránsito, coincidente con la Av. Estrada, que actúa como distribuidora de flujos (el Plan de Ordenamiento la identifica como corredor de traslado interno). Desde esta arteria se pueden visualizar pequeñas áreas abandonadas, algunas colonizadas por vegetación exótica invasora (álamos, retamas, zarzamoras).

\section{Área Sur y Sureste:}

Hacia el sudeste y sur del área consolidada se ubica un amplio sector periurbano de elevado valor asociado a la calidad paisajística de las estribaciones serranas. Las viviendas unifamiliares y conjuntos habitacionales privados de mediana a alta calidad conviven con áreas recreativas como el Parque Independencia y Lago del Fuerte, paseos con el del Bicentenario, etc. En los sectores periféricos se destacan el Barrio Golf, el Country Sierras de Tandil y Club de Golf y barrios semicerrados como Chacras del Golf, la urbanización de la Ex quinta La Rosa, el Barrio de zona Uncas. Vinculada también a la alta calidad ambiental del entorno, se concentra en el arco sur, la oferta de alojamiento turístico extrahotelero (complejos de cabañas) de los últimos años.

Zona Uncas (zona 3 en mapa $N^{\circ} 6$ )

Existe un uso residencial más intensivo con predios parquizados y arboledas, y hacia el sur-sureste aparece un uso del suelo ganadero y minero. Se accede a yacimientos en explotación (Cerro Albión) y aparecen frentes de cantera, como Interlen (pasivo minero) que en fase de abandono más reciente que otros sitios, permite observar cortes geológicos menos meteorizados.

Ofrece además usos recreativos, deportivos (golf, hockey, rugby) y de servicios turísticos (cabañas, casas de té) y esta atravesada por un circuito turístico complementario como el circuito o camino de

Publicado en formato digital: MsC Guillermina Fernández y MsC Aldo G. Ramos. EL CRECIMIENTO URBANO DE TANDIL: ¿MODELO TERRITORIAL DE LA CIUDAD DIFUSA? Revista Geográfica Digital. IGUNNE. Facultad de Humanidades. UNNE. Año 10. NN 20. Julio - Diciembre 2013. ISSN 1668-5180 Resistencia, Chaco.

En: http://hum.unne.edu.ar/revistas/geoweb/default.htm 
Los Manantiales. El Plan de Ordenamiento la incluye como área periurbana en proceso de consolidación.

\section{Zona Cerro de la Cruz (zona 4 en mapa $N^{\circ} 6$ )}

Se observa, en esta zona, una transición entre lo urbano, el periurbano y lo rural, muy asociada a la actividad recreativa del Dique Lago del Fuerte y al mirador Cervantes, así como senderos para actividades de aventura y deporte. El uso residencial ha tenido un importante avance de la construcción sobre el sector serrano. En ella se encuentran dos paredes (pertenecientes a pequeñas áreas de explotación) conocidas como Dos Huecos. El sector más lejano al centro se convierte en un periurbano, con convivencia de usos residenciales y agrícola-ganaderos.

\section{Área Este: Zona Hipódromo (zona 5 en mapa $N^{\circ} 6$ )}

Predomina el uso residencial intensivo o de alta densidad, sin edificación en altura, y hacia la periferia predomina el periurbano. Existe una problemática de desconexión de la zona con el resto de la ciudad (a pesar de tener transporte público interurbano), por la barrera que genera la RN 226 separándola del ejido urbano. Presenta sectores con ausencia de servicios (agua, cloacas) y condiciones de vivienda precaria.

Los pasivos son minas de arena abandonadas (túneles subterráneos) que ocupan tanto terrenos baldíos como el subsuelo de barrios consolidados, que experimentan problemas por inestabilidad estructural de las viviendas. El Plan de Ordenamiento identifica el área como periurbana en proceso de consolidación.

\section{Conclusiones preliminares.}

Como se puede observar en este análisis preliminar Tandil crece, sobre todo en las últimas dos décadas bajo un modelo disperso, cercano al área central, pero que no encuentra ningún tipo de barreras en los faldeos serranos. Es necesario establecer en que medida la reglamentación del Plan de Desarrollo Territorial de Tandil y la Ley provincial que lo declara Paisaje Protegido puede evitar el crecimiento del uso residencial por encima de la cota de $200 \mathrm{msnm}$, como está establecido. A priori, se observa una primer problemática que es la dotación de servicios y de infraestructuras y los costos y problemas ambientales que suponen la construcción en estas áreas. No se analizaron aún problemas en torno a la segregación espacial, de dos modelos diferentes de crecimiento, con viviendas de alto valor sobre las sierras, especulación inmobiliaria y barrios planificados en la zona Ilana. A su vez este análisis se complejiza si incorporamos dos áreas que no fueron consideradas en esta primera instancia por ausencia de cartografía temática apropiada, como la zona de Cerro Leones y la Zona Don Bosco.

Este primer avance permite iniciar la discusión de las formas de expansión de la ciudad en franjas y de forma heterogénea. El argumento original del proceso de dispersión y difusión urbana tienen su origen en la búsqueda de mejores condiciones ambientales, calidad de vida y precios del suelo más reducidos. Entonces, el modelo de crecimiento discontinuo y disperso no es, en general, el resultado de un plan que haya tenido en cuenta la disposición de las infraestructuras de transporte y la de los núcleos urbanizados. Es básicamente un modelo espontáneo que se apoya en gran medida en la gestión inmobiliaria y la actuación personal de diversos actores, lo cual implica un sprwal no programado.

\section{Referencias.}

(1) Environmental Law Institute. USA http://www.eli.org/ documentos en línea.

(2) Cerda Troncoso, J La expansión urbana discontinua analizada desde El enfoque de accesibilidad territorial Aplicación a Santiago de Chile (2007: 23)

(3) Galster, J Wrestling Sprawl to the Ground: Defining and Measuring an Elusive (2000:12)

\section{Bibliografía:}

Barnes, K., Morgan, J. Sprawl development: its patterns, consequences, and measurement Center for Geographic Information Sciences, Towson University

Publicado en formato digital: MsC Guillermina Fernández y MsC Aldo G. Ramos. EL CRECIMIENTO URBANO DE TANDIL: ¿MODELO TERRITORIAL DE LA CIUDAD DIFUSA? Revista Geográfica Digital. IGUNNE. Facultad de Humanidades. UNNE. Año 10. NN 20. Julio - Diciembre 2013. ISSN 1668-5180 Resistencia, Chaco.

En: http://hum.unne.edu.ar/revistas/geoweb/default.htm 
http://chesapeake.towson.edu/download.aps/landscape/urbansprawl/download/sprawl_white_paper.p df

Cerda Troncoso J (2007) La expansión urbana discontinua analizada desde El enfoque de accesibilidad territorial Aplicación a Santiago de Chile. Tesis de Master oficial en Gestión y Valoración Urbana. Universidad Politécnica de Cataluña Departamento de Construcciones Arquitectónicas I Centro de Políticas del Suelo y Valoraciones

Capel H (1996) La rehabilitación y el uso del patrimonio histórico industrial. Documento de Revista ANALES de Geografía N29, pp. 19-50 - Barcelona.

Galster, J et. all (2000) Wrestling Sprawl to the Ground: Defining and Measuring an Elusive Concept. Fannie Mae Foundation.

Lobato, R. Correa (1996) Territorialidade e corporação: um exemplo. In Santos, Milton et al. (orgs). Território: globalização e fragmentação. Hucitec, São Paulo, pp. 251-256

Plan de Ordenamiento Territorial (2006). Municipio de Tandil. Documento Diagnóstico.

Russi D. y J. Martínez Alier (2002) Los Pasivos ambientales. Iconos. Revista de Ciencias Sociales No 95 (Ico 15 htm). Facultad Latinoamericana de Estudios Sociales. Sede Académica de Ecuador. Quito. Pp123-131.

Zeballos de Sisto, P (2006) El riesgo ambiental minero y su regulación en Argentina estado del arte. En Seminario realizado por el Instituto de Política Ambiental de la Academia Nacional de Ciencias Morales y Políticas, el 20 de noviembre de 2006

Publicado en formato digital: MsC Guillermina Fernández y MsC Aldo G. Ramos. EL CRECIMIENTO URBANO DE TANDIL: ¿MODELO TERRITORIAL DE LA CIUDAD DIFUSA? Revista Geográfica Digital. IGUNNE. Facultad de Humanidades. UNNE. Año 10. No 20. Julio - Diciembre 2013. ISSN 1668-5180 Resistencia, Chaco.

En: http://hum.unne.edu.ar/revistas/geoweb/default.htm 